\title{
O SÍTIO ÁGUABRANCA: INTERAÇÕES CULTURAIS DOS GRUPOS CERAMISTAS NO NORTE DO ESTADO DE SÃO PAULO
}

\author{
Marisa Coutinho Afonso* \\ Camila Azevedo de Moraes**
}

\begin{abstract}
AFONSO, M.C.; MORAES, C.A. O sítio Água Branca: interações culturais dos grupos ceramistas no norte do estado de São Paulo. Rev. do Museu de Arqueologia e Etnologia, São Paulo, 1516:59-71, 2005-2006.
\end{abstract}

RESUMO: O objetivo deste trabalho é discutir as ocupações ceramistas não associadas à tradição Tupiguarani no norte do estado de São Paulo, que evidenciam uma influência dos grupos habitantes do Planalto Central brasileiro, com uma ênfase especial na análise do sítio arqueológico Água Branca, localizado em Casa Branca (SP) e também outros sítios que foram objeto de uma nova análise à luz de problemáticas identificadas recentemente.

UNITERMOS: Cerâmica - Interação cultural - São Paulo.

\section{Introdução}

O objetivo deste trabalho é discutir as ocupações ceramistas não associadas à tradição Tupiguarani no norte do estado de São Paulo, que evidenciam uma influência dos grupos habitantes do Planalto Central brasileiro, com uma ênfase especial na análise do sítio Água Branca, localizado em Casa Branca (SP) e também outros sítios que foram objeto de uma nova análise à luz de problemáticas identificadas recentemente.

Robrahn-González (2000) discutiu as indústrias notadamente diversas dos cerca de 200 sítios cerâmicos conhecidos em São Paulo até 1997. Agrupou-as em três grandes unidades classificatórias: a tradição Tupiguarani, mais antiga,

(*) Museu de Arqueologia e Etnologia da Universidade de São Paulo.marisa@br2001.com.br

(**) Museu de Arqueologia e Etnologia da Universidade de São Paulo. Pós-Graduação. Mestrado. Bolsista FAPESP. camora21@yahoo.com.br com vestígios que se distribuem por todo o estado de São Paulo; a tradição Itararé, com sítios localizados na porção sul, e a tradição AratuSapucaí, com sítios na região norte. A autora indicou a região sul de São Paulo como área de fronteira entre grupos Guarani, ao sul, e Tupinambá, ao norte; a tradição Itararé, relacionada a um contexto de tradições ceramistas do sul do Brasil, apresentaria seu limite setentrional no estado de São Paulo. No caso da tradição Aratu-Sapucaí, vinculada a sítios localizados nas regiões centrooeste e nordeste do Brasil, o norte de São Paulo representa sua manifestação mais meridional.

Na região norte-nordeste do estado de São Paulo foram localizados sítios não filiados à tradição ceramista tupiguarani na bacia do rio Paraíba do Sul (nordeste do estado) e na bacia do rio Grande (ao norte).

O sítio Maranata, situado no município de Olímpia, na bacia do rio Grande e pesquisado por Silvia Maranca (MAE/USP), foi filiado à tradição Aratu-Sapucaí, com base na reconstituição das formas dos vasilhames (Maranca, Silva \& Scabello 
AFONSO, M.C.; MORAES, C.A. O sítio Água Branca: interações culturais dos grupos ceramistas no norte do estado de São Paulo. Rev. do Museu de Arqueologia e Etnologia, São Paulo, 15-16: 59-71, 2005-2006.

1994), e constituiu o primeiro sítio desta tradição localizado no estado de São Paulo.

O sítio Caçapava I foi o primeiro a ser identificado na bacia do rio Paraíba do Sul, durante os estudos arqueológicos para o licenciamento ambiental da Rodovia Carvalho Pinto pela Scientia Consultoria, em projeto coordenado por Solange Bezerra Caldarelli. Segundo Caldarelli (1999: 356), "o único sítio indígena localizado, no município de Caçapava, pertence à tradição cerâmica Aratu, variedade Sapucaí, apresentando mais de trinta sepultamentos em urnas funerárias não decoradas. Objeto de resgate em 1991, foi o primeiro sítio desta tradição escavado exaustivamente no estado de São Paulo".

Este sítio é multicomponencial e descrito como um conjunto de residências históricas, justaposto e parcialmente sobreposto a um assentamento indígena ceramista; sua cultura material é variada e apresenta cerâmica (pré-colonial e histórica), material lítico (lascado e polido), louça, vidro, objetos de metal, restos vegetais (carvão), de animais (conchas e placas de carapaça de tatu) e esqueletais humanos (Caldarelli 2003a).

Gomes (2003), após a análise da cerâmica indígena deste sítio, comparou-a com as informações bibliográficas sobre a tradição Aratu e concluiu que é possível associar a indústria cerâmica do sítio Caçapava 1 a esta tradição, mas pelas características morfológicas, a vinculação desta cerâmica à variedade Sapucaí parece ser mais tênue do que comparada à cerâmica Aratu do Planalto Central.

Como características principais da cerâmica estudada por Gomes (2003) podem ser citadas: o uso do acordelamento, de antiplástico mineral, queima incompleta em 82\% da amostra (possivelmente elaboradas em fornos de cova), bom alisamento em ambas as faces, sem emprego de engobo vermelho ou decorações plásticas, espessuras de até $1 \mathrm{~cm}$ para $60 \%$ das peças. Quanto às vasilhas, aquelas recuperadas em contexto funerário podem ter sido usadas para armazenamento de alimentos sólidos ou líquidos; há vasilhas para cozimento (formas esféricas ou semi-esféricas) e também para servir (maior diâmetro é da boca).

Seis datações, sendo duas pelo método Carbono 14 e 4 por AMS, apresentaram para cinco diferentes urnas as seguintes datas: $870 \pm 40$ $\mathrm{AP}, 660 \pm 40 \mathrm{AP}, 620 \pm 40 \mathrm{AP}, 610 \pm 50 \mathrm{AP} 600$ \pm 60 AP e para um forno: $590 \pm 50$ AP (Caldarelli 2003b). As datações absolutas obtidas para o sítio Caçapava 1 confirmam, segundo a autora, a presença no vale do Paraíba de populações indígenas da tradição Aratu por quase três séculos (a ocupação teria acontecido do século XI à primeira metade do século XV). O grande número de estruturas funerárias e os poucos artefatos de uso cotidiano indicaram também que o sítio devia ter um significado especial para a antiga população indígena já que houve enterramentos no local por trezentos anos.

O sítio Água Limpa, situado no Município de Monte Alto, bacia do Rio Grande, foi objeto de escavação no Projeto Turvo, coordenado por Márcia Angelina Alves (MAE/USP). Trata-se de um sítio a céu aberto, que apresenta estruturas de combustão, sepultamentos primários de indivíduos adultos, sepultamentos secundários e restos alimentares (Alves e Calleffo 1996).

Neste sítio foram encontradas três estruturas habitacionais, de formato ovalado, consideradas como residências comunais, com fogueiras internas e externas às habitações. Duas práticas funerárias coexistiam: onze sepultamentos primários foram localizados na periferia do sítio e urnas funerárias de cerâmica com ossos de indivíduos adultos fora do setor habitacional. A presença na cerâmica de urnas globulares, formas duplas e vasilhas esféricas com borda extrovertida levaram a sua filiação à tradição Aratu-Sapucaí embora haja também atributos decorativos (pintura em faixas vermelhas) e morfológicos (bases planas e formas de perfil complexo) como possíveis indicadores de influências externas (Fernandes 2001).

Para o sítio Água Limpa há datas de $1524 \pm$ 215 AP a $375 \pm 40$ AP sinalizando uma ocupação por um período longo do século $\mathrm{V}$ ao século XVII, embora os materiais mais vinculados à tradição Aratu-Sapucaí tenham apresentado as seguintes datas: $720 \pm 70$ AP para uma borda ondulada e $456 \pm 50$ AP.

O sítio Água Vermelha 2, localizado no município de Ouroeste, no norte de São Paulo, no limite com o estado de Minas Gerais (RobrahnGonzalez, Afonso, De Blasis, Figuti, Neves, Eggers 1998) é uma aldeia extensa, apresentando vestígios cerâmicos morfologicamente associados à tradição Aratu-Sapucaí, com formas duplas, sem decoração e antiplástico composto por mineral, caco-moído e cariapé. Também apresenta formas 
de contorno simples (vasilhas de meia elipse, cônicas e semi-esféricas) e infletido (forma esférica e forma oval), sendo que as vasilhas rasas (tigelas) serviriam ao preparo e ao consumo de alimentos e as de contorno infletido à cocção. Segundo Robrahn-Gonzalez et alii (1998), a ocupação do sítio Água Vermelha 2 estaria relacionada ao processo de diversificação cultural ocorrido na região centro-oeste, entre os séculos IX e X. Algumas características da cerâmica, como o uso do caco moído como antiplástico e as formas compostas, seriam associadas à influência Tupi e o uso de cariapé aos Grupos Uru, indicando cerâmicas de origens variadas como encontradas no Brasil Central. A cronologia do sítio (1010 \pm 50 BP e 700 $\pm 70 \mathrm{BP}$ ) indicaria uma rapidez no processo de diversificação cultural.

Nas proximidades do sítio Água Vermelha 2, há um sítio com características da tradição Uru, o sítio Água Vermelha 1:"Embora sua cerâmica apresente características que remetem à tradição Tupiguarani, a forte presença do antiplástico cariapé, bem como de lâminas de machado meia-lua, remetem a um contexto a Oeste do Araguaia, relacionado aos grupos portadores de cerâmica Uru." (RobrahnGonzalez, Afonso, De Blasis, Figuti, Neves, Eggers 1998: 68)

O sítio Light, localizado no município de Jacareí, na bacia do rio Paraíba do Sul, foi pesquisado por Wagner Bornal e relaciona-se à tradição Aratu. Segundo Gomes (2003, apud Bornal 2000), o sítio Light é unicomponencial e apresenta formas e atributos típicos da tradição Aratu. Apresentou vasilhas esféricas de base cônica, cilíndricas de contorno infletido com base cônica, ovóides e semi-esféricas e um cachimbo tubular. Também foram encontrados fragmentos com decoração plástica corrugada, ungulada, pintura vermelha sobre branco indicando contato como grupos Tupi-Guarani. Neste sítio, foram observadas vasilhas em contexto funerário, com restos humanos.

De acordo com Gomes (2003), urnas de formatos semelhantes (urna de perfil infletido e corpo cilíndrico e urna de formato ovóide) foram encontradas no sítio Light e no sítio Caçapava I e estas semelhanças poderiam ser interpretadas como uma característica regional da cerâmica, indicando contemporaneidade parcial, ou a presença de grupos multi-étnicos vindos de levas migratórias.

\section{O sitio Água Branca: novos dados sobre a ocupação do nordeste do estado}

O sítio Água Branca foi localizado no Município de Casa Branca, na bacia do rio Pardo, afluente do rio Grande, durante o desenvolvimento do projeto "Levantamento arqueológico na faixa de domínio da duplicação da Rodovia SP-340: km 236,8 e 281,7" pela equipe da Scientia Consultoria Científica S/C Ltda., coordenada por Solange Bezerra Caldarelli (Scientia, 2000). Situa-se no lado esquerdo da rodovia SP-340 (sentido Casa Branca-Mococa, pista sul), próximo ao km 250 (coordenadas UTM E = $286.551 \mathrm{~m} \mathrm{e} \mathrm{N}=$ 7.602.286), à margem direita do córrego Água Branca, ocupando as partes baixa e média de uma vertente de inclinação suave.

Para o salvamento dos sítios encontrados, foi elaborado o projeto "Resgate Arqueológico dos Sítios Água Branca, Lambari I e Lambari II, Municípios de Casa Branca e Mococa - SP” através do contrato firmado entre o Museu de Arqueologia e Etnologia da Universidade de São Paulo e Renovias Concessionária S.A., de março a outubro de 2001, sob a coordenação de Marisa Coutinho Afonso e vice-coordenação de José Luiz de Morais.

O sítio Lambari I está relacionado à ocupação da região por grupos caçadores-coletores, sendo caracterizado pela presença de artefatos lascados em silexito. O sítio Lambari II, por sua vez, encontra-se a cerca de $1 \mathrm{~km}$ do sítio Água Branca e apresentou material nitidamente associado à tradição Tupiguarani. ${ }^{1}$

No caso do sítio Água Branca, vestígios arqueológicos, especialmente cerâmicos, foram identificados na faixa de domínio da rodovia e também na propriedade agrícola contínua, com plantação de algodão. Além da cerâmica, apresentou também vários artefatos líticos polidos como lâminas de machados polidos e um virote de sílex, além de artefatos líticos lascados.

A equipe de arqueologia fez o levantamento das faixas de domínios dos dois lados da estrada, da área cultivada até o córrego Água Branca a oeste e da área cultivada a leste. A distribuição dos materiais arqueológicos em superfície foi delimitada

(1) Esse sítio compõe a pesquisa de mestrado desenvolvida por uma das autoras (Moraes 2006). 
através de caminhamento intensivo, com o auxílio das bandeiras de plástico fincadas nos locais onde foram localizados os vestígios (de cor amarela para cerâmica e branca para lítico).

Sete sondagens foram realizadas na faixa de domínio e três na área cultivada em posições topográficas diferentes na vertente, sendo a última próxima da mata galeria do córrego Água Branca. A profundidade das sondagens variou de $0,80 \mathrm{~m}$ até 1,30 m, dependendo do tipo de solo; machados polidos inteiros foram localizados em duas.

A coleta total dos vestígios arqueológicos foi realizada com auxilio da Estação Total permitindo a localização peça a peça, visando a uma melhor compreensão da organização espacial através de uma análise intra-sítio. Todos os materiais arqueológicos (cerâmicas, líticos lascados e polidos) foram coletados, numerados e obtidas suas coordenadas x e y, necessárias para a confecção de plantas topográficas do sítio (Fig. 1). Planejou-se fazer um ensaio metodológico de forma a se dispensar o quadriculado (a malha de coleta) no terreno, cuja realização envolveria muito tempo da equipe e seria difícil de ser executado devido aos restos da plantação de algodão após a colheita.

Foram confeccionadas plantas com o mapeamento de todos os vestígios e separando-os por categoria. A planta do sítio, com a indicação das áreas de maior concentração de cerâmica, revelou uma estrutura elíptica com eixos de 200 metros por 140 metros. Observa-se que a maior parte do sítio encontra-se na área cultivada e não na faixa de domínio, ou seja, a construção da estrada há décadas e depois a sua duplicação recente afetaram apenas a periferia do sítio.

A morfologia do assentamento com forma anular aproxima o sítio Água Branca dos grupos ceramistas do Centro-Oeste que apresentam casas ao redor de uma praça central, com uma saída em direção ao córrego. Segundo Prous, verifica-se nesse padrão de assentamento das aldeias uma correspondência com a zona ocupada no período histórico pelos Caiapós e evidências do tipo Aratu (Prous 1992: 349), fato a ser discutido adiante.

\section{A indústria cerâmica do sítio Água Branca}

A cerâmica do sítio Água Branca logo chamou a atenção dos arqueólogos, tanto da equipe do levantamento (Scientia) quanto do resgate (MAE/
USP) por vários motivos: a maior parte dos fragmentos é lisa, sem decoração, com pequenas dimensões e, o mais surpreendente, apresenta cariapé como antiplástico. O conjunto analisado corresponde a 1192 peças provenientes da coleta ponto a ponto com Estação Total e a 179 peças provenientes de sondagens, totalizando 1371 fragmentos. A Tabela 1 mostra a distribuição dos fragmentos por classe.

TABELA 1

\begin{tabular}{lrr}
\hline \multicolumn{3}{c}{ Classes dos fragmentos cerâmicos } \\
\hline \multicolumn{1}{c}{ Classe } & Total & \multicolumn{1}{c}{ \% } \\
\hline \hline Paredes Simples & 1119 & 81,62 \\
Bordas & 122 & 8,90 \\
Bases & 31 & 2,26 \\
Micro-cerâmicas & 88 & 6,42 \\
Paredes com aplique & 3 & 0,22 \\
Ombros & 6 & 0,44 \\
Fragmentos de vasilhas com & & \\
formas duplas & 2 & 0,15 \\
Total & $\mathbf{1 3 7 1}$ & $\mathbf{1 0 0 , 0 0}$ \\
\hline
\end{tabular}

As micro-cerâmicas correpondem a fragmentos de paredes diminutos (com menos de $1 \mathrm{~cm}$ ), que não foram alvo de análise pormenorizada. As demais peças (1283 unidades analíticas) passaram por uma análise sistemática que envolveu 24 atributos, ${ }^{2}$ baseada em Arnold 1985; Chymz 1976; Rice 1987; Rye 1981; Robrahn-González 1996; Sinopoli 1991; Skibo 1992 e Wüst 1990.

Com relação à técnica de construção foi constatada uma boa junção dos roletes, obliterados em $95 \%$ das peças. A técnica modelada foi identificada em apenas $0,4 \%$ das peças, revelando o predomínio da técnica acordelada. No que tange à espessura da vasilhas tem-se: $3 \%$ com $0-4 \mathrm{~mm} ; 24 \%$ com 4-6mm; 30\% com 6-8mm; 24\% com 8-10mm;

(2) Classe; Espessura da Peça; Técnica de Construção; Forma da Borda; Espessura da Borda em Relação ao Corpo; Diâmetro da Boca; Porcentagem existente da Borda; Forma de Lábio; Espessura do Lábio; Forma da Base; Diâmetro da Base; Porcentagem existente da Base; Ângulo da Base; Antiplástico; Espessura do Antiplástico; Freqüência do Antiplástico; Tipo de Pasta; Queima; Acabamento de Superfície; Cor da Superfície; Engobo; Decoração; Tipo de Decoração e Estado de Conservação da Peça. 


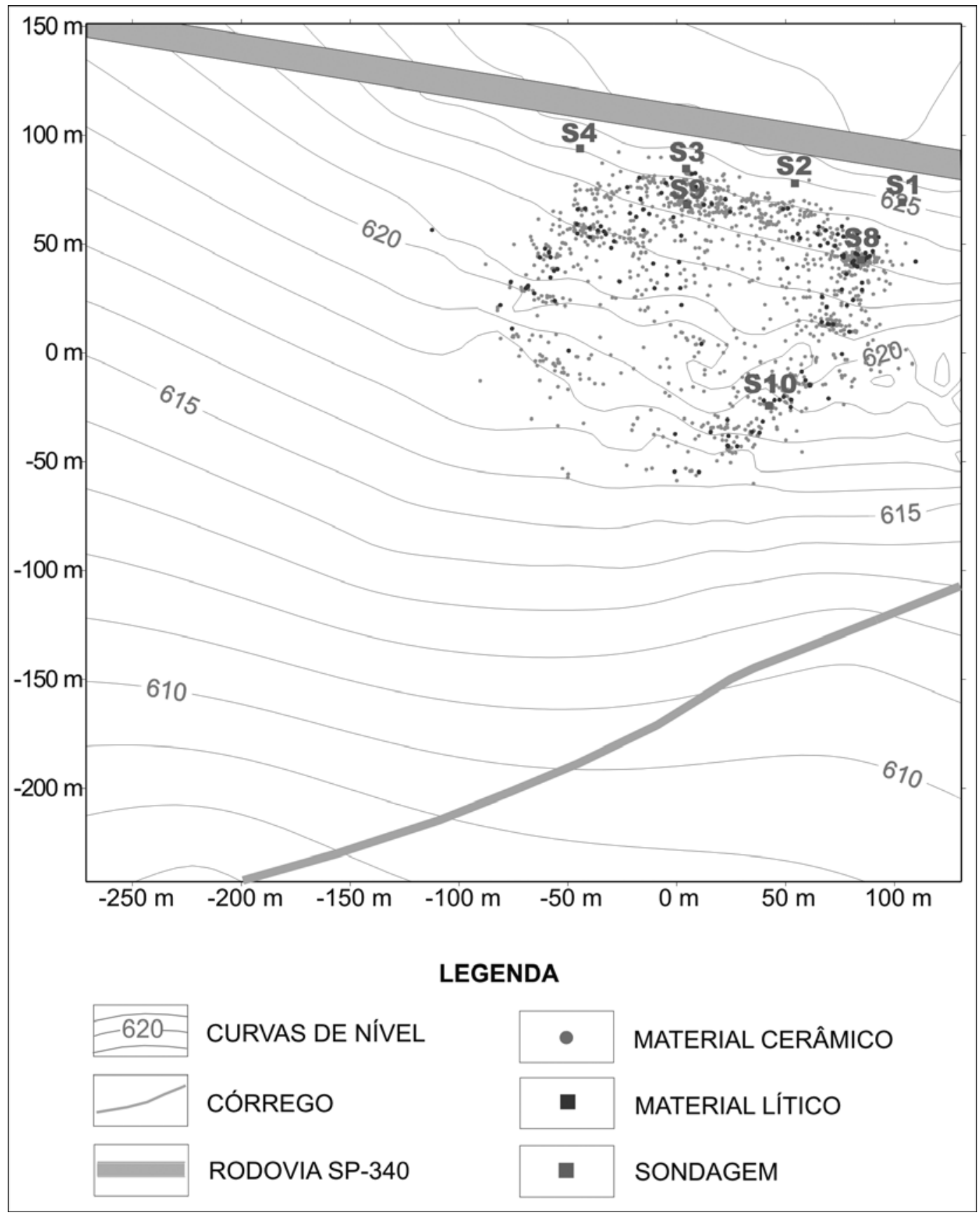

Fig. 1 - Planta do sítio Água Branca com a localização das peças em superfície e sondagens positivas.

$13 \%$ com $11-12 \mathrm{~mm}$ e $6 \%$ com mais de $13 \mathrm{~mm}$. A análise dos antiplásticos está apresentada na Tabela 2.

Optou-se pela diferenciação de dois tipos de pasta com antiplástico mineral, o Mineral 1 está associado à presença esparsa de grãos arrendondados de quartzo e hematita e o antiplástico Mineral 2 está relacionado à presença abundante de partículas leitosas arredondadas e alongadas, cuja 
AFONSO, M.C.; MORAES, C.A. O sítio Água Branca: interações culturais dos grupos ceramistas no norte do estado de São Paulo. Rev. do Museu de Arqueologia e Etnologia, São Paulo, 15-16: 59-71, 2005-2006.

TABELA 2

\begin{tabular}{lrr}
\hline \multicolumn{3}{c}{ Tipo do antiplástico } \\
\hline \multicolumn{1}{c}{ Tipo } & Total & \multicolumn{1}{c}{$\mathbf{\%}$} \\
\hline \hline Mineral 1 & 72 & 5,61 \\
Mineral 2 & 545 & 42,48 \\
Cariapé & 490 & 38,19 \\
Caco-Moído & 174 & 13,56 \\
Cariapé e Caco-Moído & 2 & 0,16 \\
Totais & $\mathbf{1 2 8 3}$ & $\mathbf{1 0 0 , 0 0}$ \\
\hline
\end{tabular}

morfologia e distribuição levou à possibilidade de as mesmas não se tratarem de partículas minerais. As análises realizadas no Microscópio de Varredura Eletrônica ${ }^{3}$ revelaram a composição mineral dessas partículas, sendo que as com morfologia cilíndrica e alongada são compostas unicamente por Silício (Si) e Oxigênio (O). Essa composição é a mesma do quartzo, mas a morfologia cilíndrica e alongada revela um processo específico de formação desse mineral.

O cariapé evidenciado é composto por duas partículas de origem vegetal, das quais uma corresponde a filamentos silicosos de cor cinza e a outra a filamentos cilíndricos de cor branca de superfície brilhante, às vezes associados a partículas pretas. Esse cariapé espesso, visível a olho nu, parece assemelhar-se ao Cariapé A descrito por Wüst (1990).

Conforme indicado na Tabela 2 o grupo ceramista do sítio Água Branca adicionou o cariapé em $38 \%$ e caco-moído em $13 \%$ das peças, sendo que apenas duas peças possuem o cariapé e $o$ caco-moído associados. Essa diferenciação pode estar relacionada à funcionalidade das vasilhas produzidas (SKIBO 1992).

Com relação à queima foi verificado que $3 \%$ das peças apresentaram secção transversal sem presença de núcleos e com coloração alaranjada; $21 \%$ das peças têm seç̧ão transversal escura e sem presença de núcleos e, por fim, 76\% das

(3) As análises foram efetuadas no Laboratório de Caracterização Tecnológica (LCT), no Departamento de Engenharia de Minas e de Petróleo da Escola Politécnica da Universidade de São Paulo. A preparação das amostras e o acompanhamento na utilização do Microscópio de Varredura Eletrônica foram realizados por Eliana Satiko Mano, pesquisadora do LCT. O Prof. Dr. Henrique Kahn, diretor do Laboratório de Caracterização Tecnológica, autorizou o uso do equipamento. peças revelaram a presença de núcleo central evidenciando queimas incompletas.

O acabamento de superfície por excelência é o alisado, seguido do banho. Foi verificada a ocorrência de brunidura em seis peças, assim como a aplicação ocasional de engobo vermelho na superfície externa de algumas peças (Figs. 2-4).
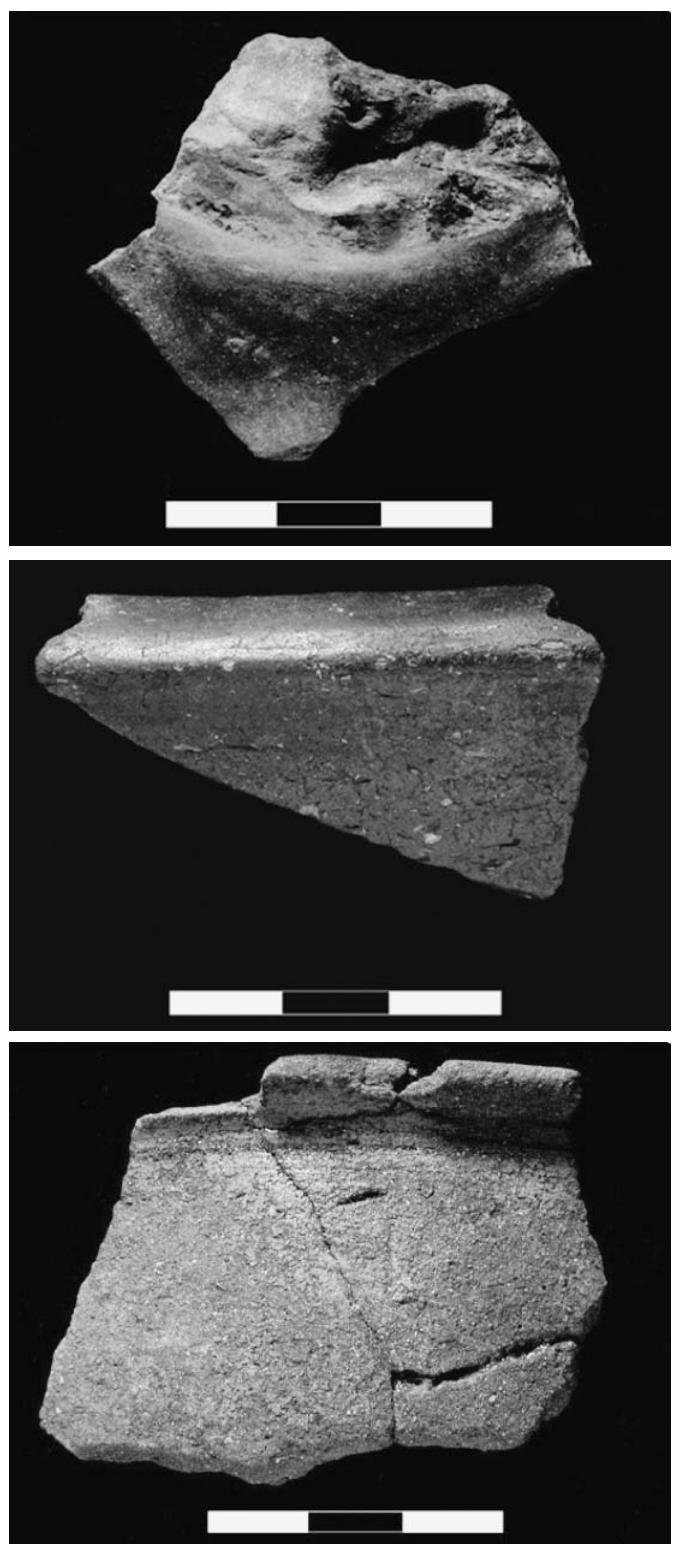

Figs. 2-4 - Parede com aplique, borda expandida com superfície brunida e borda extrovertida com engobo vermelho externo. 
De um total de 122 bordas presentes no sítio, 58 peças possibilitaram a classificação de morfologia e diâmetro. Optou-se, no estágio atual da pesquisa, pela não reconstituição das formas dadas as dimensões diminutas das bordas evidenciadas e 0 fato de se estar lidando com uma indústria cerâmica até então desconhecida, não existindo parâmetros para a realização de reconstituições seguras das vasilhas inteiras. Não obstante, as bordas desenhadas foram agrupadas de acordo com sua forma e inclinação (Fig. 5), resultando na formação de seis grupos com características morfológicas semelhantes (Tabela 3).

O diâmetro variou entre 8 e $36 \mathrm{~cm}$, sendo que apenas duas peças possuíram diâmetro maior que $26 \mathrm{~cm}$, ambas associadas a estruturas abertas.

Houve um predomínio dos lábios arredondados (cerca de 69\% das peças), mas há uma presença significativa de lábios planos (cerca de $24 \%$ das peças), esses sempre relacionados à bordas diretas com reforço (Grupo 2).

Foram identificadas apenas 31 bases, sendo que $85 \%$ dessas peças são planas. Apenas doze peças, todas planas, possibilitaram a medida de seus respectivos diâmetros: seis com diâmetros de 10 a $18 \mathrm{~cm}$; cinco com diâmetros de 20 a $26 \mathrm{~cm}$ e apenas uma peça com diâmetro de $40 \mathrm{~cm}$. Vale destacar que $80 \%$ das bases planas apresentam ângulo de $90^{\circ}$ (Figs. 6 e 7). Uma das bases, pertencente a um prato, apresenta características que diferem do conjunto artefatual do sítio, como a pasta e o tratamento de superfície. Essa peça guarda semelhanças com o material cerâmico da tradição Tupiguarani e pode ser um vestígio de um fluxo de objetos com outros grupos da região. Futuras pesquisas poderão elucidar se houve uma ocupação concomitante de grupos associados aos Macro-Jê e os grupos Tupi na área.

Algumas funções hipotéticas, com base nos dados fornecidos por Rice (1987), podem ser sugeridas. O Grupo 1, com formas abertas e dimensões predominantemente pequenas e tratamentos de superfície aprimorados, deve estar relacionado ao consumo de alimentos e/ou bebidas; os Grupos 2 e 3 com formas abertas ou levemente restritas podem ser associados, por sua vez, ao serviço e/ou preparo de alimentos, apresentando dimensões medianas e grandes e, por fim, os Grupos 4, 5 e 6 evidenciam formas fechadas destinadas ao armazenamento e/ou cocção de alimentos e/ou bebidas. Vale destacar que o antiplástico vegetal (cariapé) está predominantemente relacionado a bordas dos Grupos 1, 2 e 3, enquanto o antiplástico mineral ou de cacomoído é o mais recorrente nos demais grupos, evidenciando escolhas relacionadas às características de performance diferenciadas desses materiais (Skibo 1992).

TABELA 3

\begin{tabular}{|c|c|c|c|c|c|}
\hline \multicolumn{6}{|c|}{ Atributos morfológicos das bordas } \\
\hline Grupo & Estrutura Geral & Morfologia da Borda & Lábio & $\begin{array}{c}\text { Diâmetro } \\
\text { de Boca }\end{array}$ & Total \\
\hline 1 & Aberta & Extrovertida Inclinada Externa & Arredondado & $8-18 \mathrm{~cm}$ & 6 \\
\hline 2 & $\begin{array}{c}\text { Aberta ou } \\
\text { Levemente Restringida }\end{array}$ & $\begin{array}{l}\text { Direta Inclinada Externa com } \\
\text { Reforço Externo; Direta Inclinada } \\
\text { Externa com Reforço Interno; } \\
\text { Direta Inclinada Externa } \\
\text { Expandida }\end{array}$ & $\begin{array}{l}\text { ou Apontado } \\
\text { Plano }\end{array}$ & $16-32 \mathrm{~cm}$ & 13 \\
\hline 3 & Aberta & Direta Inclinada Externa & $\begin{array}{l}\text { Arredondado } \\
\text { ou Apontado }\end{array}$ & $14-36 \mathrm{~cm}$ & 8 \\
\hline 4 & Fechada & $\begin{array}{c}\text { Extrovertida Vertical; } \\
\text { Extrovertida Inclinada Externa }\end{array}$ & $\begin{array}{l}\text { Arredondado } \\
\text { ou Apontado }\end{array}$ & $10-18 \mathrm{~cm}$ & 10 \\
\hline 5 & Fechada & $\begin{array}{l}\text { Direta Inclinada Interna; Direta } \\
\text { Inclinada Interna Expandida }\end{array}$ & Arredondado & $8-20 \mathrm{~cm}$ & 13 \\
\hline 6 & Fechada & Direta Inclinada Interna & Arredondado & $16-20 \mathrm{~cm}$ & 8 \\
\hline
\end{tabular}




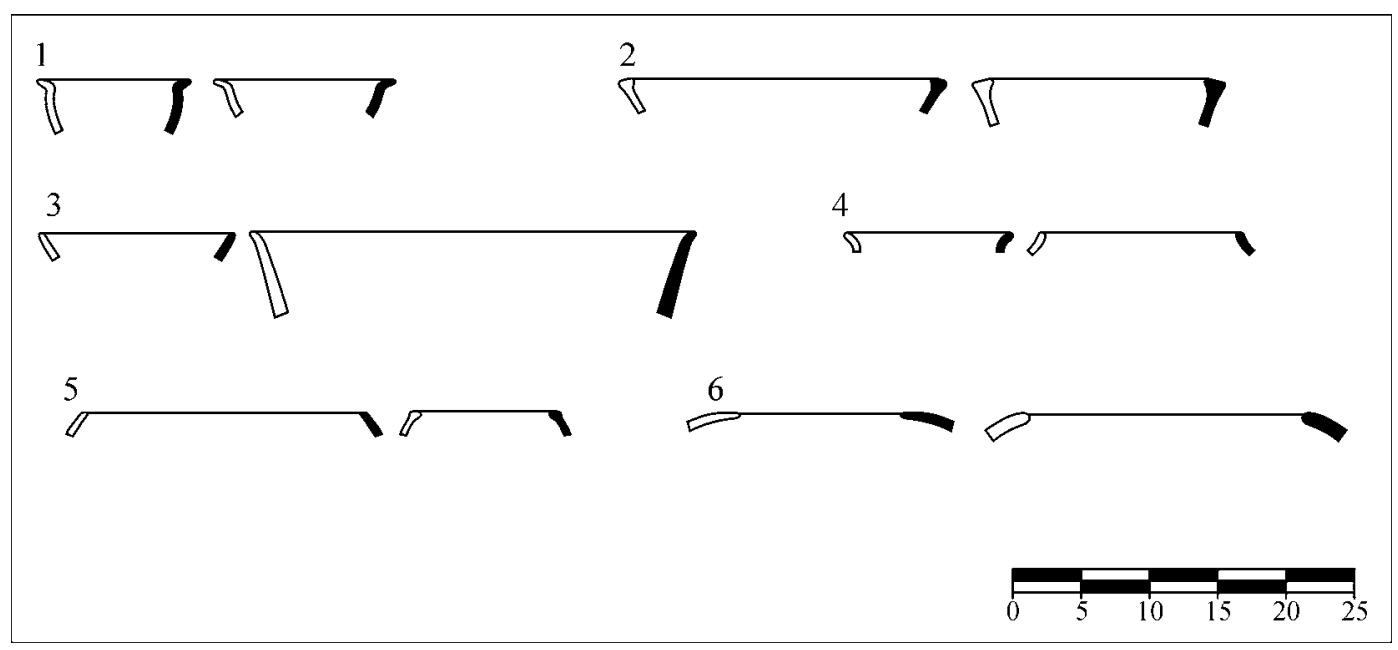

Fig. 5 - Grupos estabelecidos a partir do desenho do perfil das bordas.

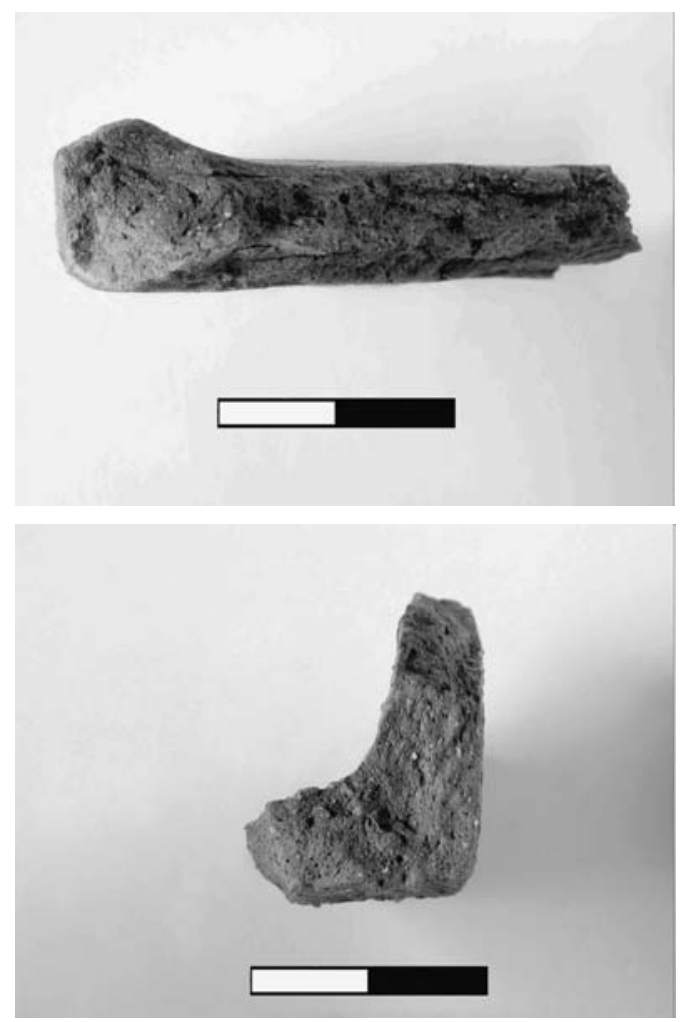

Figs. 6 e 7 - Bases Planas.

Concluindo, a análise detalhada da cerâmica identificou características das tradições AratuSapucaí (fragmentos indicadores de formas duplas, apliques), Tupiguarani (caco moído na pasta, ombros indicando vasos de formas compostas) e Uru (cariapé, bases planas com ângulos de $90^{\circ}$ ) no material do sítio Água Branca, evidenciando a insuficiência do conceito de tradição arqueológica em contextos de intensa diversificação cultural. Ademais, a análise desse sítio demonstra que o norte do estado de São Paulo foi palco de ocupações ceramistas diferenciadas, ainda pouco estudadas, mas cada vez mais recorrentes nas pesquisas realizadas no interior paulista, como indicados por outros sítios arqueológicos.

\section{Outros sítios com indústrias cerâmicas diferenciadas}

Além dos sítios diversificados presentes na bibliografia sumarizada no início desse artigo, outros assentamentos demonstram a complexidade das ocupações ceramistas no norte do estado. O estudo do sítio Água Branca levou a uma nova análise de alguns sítios localizados no norte do estado de São Paulo em projetos anteriores, como os sítios Lagoa Preta I, datado de 280 AP, e Lagoa Preta II, filiados à denominada "tradição Neobrasileira”. ${ }^{4}$

(4) Para uma avaliação critica desse rótulo: Zanettini \& Moraes 2005; Zanettini 2005. 
O vale médio do rio Pardo, no norte do estado de São Paulo, foi objeto de investigações arqueológicas acadêmicas durante a década de 1980, quando foi desenvolvido o "Programa de Pesquisas Arqueológicas no Vale Médio do Rio Pardo, SP” pelo Instituto de Pré-História da USP, sob coordenação de Solange Bezerra Caldarelli e Walter Alves Neves (Caldarelli \& Neves 1981; Caldarelli 1983; Afonso 1988, 1989). Os trabalhos permitiram detectar $\mathrm{o}$ alto potencial arqueológico da região com pesquisas em sítios localizados nos municípios de São Simão, Serra Azul, Cajuru, Luís Antônio e Jardinópolis. Foram identificados sítios líticos, sítios cerâmicos filiados às tradições Tupiguarani, “Neobrasileira” e uma não identificada na época, e três sítios com gravuras rupestres (petróglifos).

Nesse Programa foram identificados quatro sítios cerâmicos relacionados à bacia do rio Pardo sendo três filiados à referida "tradição Neobrasileira" pelas características da cerâmica e pela datação, sítio Lagoa Preta I, com 280 anos AP, Lagoa Preta II e Bebedouro da Pedra, localizados no município de Serra Azul (Caldarelli \& Neves 1981) e um quarto sítio, Tamanduazinho, no município de São Simão, com características não semelhantes à cerâmica da tradição Tupiguarani e uma amostra coletada para datação resultou em $990 \pm 70$ anos AP (Afonso 1988).

Os vestígios cerâmicos dos sítios Lagoa Preta I, II e Bebedouro da Pedra foram analisados em laboratório, mas no caso do sítio Tamanduazinho, houve apenas uma pequena intervenção em campo que resultou no reconhecimento da sua cerâmica como não tupi e na coleta de material para datação. Este sítio era o único cerâmico localizado no município de São Simão onde já havia sido localizado um número expressivo de sítios líticos relacionados à ocupação de caçadores-coletores.

Os vestígios dos sítios Lagoa Preta I e II foram retomados e essa nova análise indicou que não se trata de sítios associados à "tradição Neobrasileira”. Moraes (2003), analisando este material, observou que não apresenta características que denotem influência européia na indústria cerâmica. O material dos sítios Lagoa Preta I e II apresenta inúmeras semelhanças com a cerâmica do Água Branca como presença de cariapé, bases planas, ausência de decoração e acabamento de superfície alisado. Essas semelhanças, aliadas às datas relativamente próximas, indicam que ambos os sítios podem ter feito parte de um mesmo sistema regional de povoamento.
Algumas pesquisas realizadas na região, sendo a maior parte no escopo da arqueologia preventiva, têm registrado sítios com indústrias cerâmicas diferenciadas.

Durante o diagóstico arqueológico realizado no gasoduto Matão-Luis Antônio, que intercepta os territórios municipais de Matão, Araraquara, Rincão, Guatapará e Luiz Antônio, foram identificados quatro sítios arqueológicos: três lito-cerâmicos e um lítico. Os sítios cerâmicos, denominados Rancho Queimado 1, 2 e 3, apresentaram fragmentos com características diferenciadas, semelhantes aos sítios Água Branca, Lagoa Preta I e Lagoa Preta II (Zanettini Arqueologia 2005), mas ainda não foram alvo de resgate arqueológico.

Os trabalhos de resgate arqueológico em área destinada à implantação de uma ponte sobre o Rio Mogi-Guaçu e uma alça de um acesso de $2 \mathrm{~km}$, em Cachoeira de Emas, município de Pirassununga, possibilitaram a pesquisa de dois sítios arqueológicos (Zanettini \& Moraes 2006). O resgate do sítio Cachoeira de Emas 1 revelou uma indústria cerâmica semelhante àquela proveniente dos sítios Água Branca e Lagoa Preta I e II, além de apresentar uma quantidade significativa de artefatos líticos lascados em silexito, não associados à tradição Tupiguarani. O sítio Cachoeira de Emas 2 apresentou, por sua vez, material cerâmico relacionado à tradição Tupiguarani, sendo incorporado ao trabalho desenvolvido por Moraes (2006). Godoy, ao realizar pesquisas na área da Cachoeira de Emas, registrou a presença de lâminas de machado com formato semi-lunar (Godoy 1974: 199), comumente associadas a grupos Macro-Gê. O mesmo autor também indica a presença de virotes, como aquele encontrado no sítio Água Branca.

O material resgatado nos sítios Pitangueiras 1, 2, no muncípio homônimo, acessado no Museu Voluntários da Pátria, ${ }^{5}$ em Araraquara, apresenta também características diferenciadas, como por exemplo: a presença de antiplástico vegetal, decorações plásticas - inclusive ponteadas,

(5) Esse material foi resgatado pela empresa Documento Arqueologia e Antropologia, mas não foi possível acessar ainda o relatório final do trabalho, em fase de conclusão. Assim, as observações estão baseadas unicamente na observação desse material, sob a salvaguarda do Museu Voluntário da Pátria. 
engobo e bordas diretas com reforço. No entanto, esse material apresenta uma diversidade decorativa impressionante, diferindo nesse aspecto do sítio Água Branca.

Por fim, vale destacar que no desenvolvimento da tese de doutoramento de Schiavetto (2005), a autora realizou pesquisas no Médio Jacaré-Guaçu e Mogi-Guaçu e constatou também a presença tanto de sítios associados à tradição Tupiguarani como de sítios com indústrias cerâmicas diversificadas.

\section{Considerações finais}

A análise do sítio Água Branca mostrou que esse sítio está associado a uma ocupação ceramista que, até o momento, não havia sido reconhecida arqueologicamente na região.

Caldarelli \& Neves (1982: 35) já haviam apontado, com relação à ocupação da região, que "quanto aos horticultores, nitidamente representados na área por duas ocupações distintas, uma Gê e uma Tupi-Guarani, a problemática que se nos apresenta atualmente é de ordem cronológi$c a$ ". Os autores referem-se aos documentos históricos que mencionam apenas índios do grupo lingüístico Gê, genericamente denominados de Caiapó, concluindo que os Tupi-Guarani já não se encontrariam na área quando da ocupação branca. Concluem que haveria uma ocupação da área com os Tupi-Guarani no vale do rio Mogi Guaçu e os Gê no vale do rio Pardo.

As características da cerâmica, a datação recente (205 \pm 20 anos AP por termoluminescência para um fragmento cerâmico), a morfologia aproximadamente circular da aldeia e os dados levantados pela pesquisa etnohistórica indicaram que o grupo que ocupou o sítio Água Branca está associado à ocupação Gê da região.

Assim, os sítios Maranata (Olímpia), Água Limpa (Monte Alto), Água Branca (Casa Branca), Lagoa Preta I, Lagoa Preta II, Tamanduazinho (São Simão) na bacia do rio Grande, o sítio Cahoeira de Emas 1 na Bacia do Mogi Guaçu, além dos sítios Caçapava I e Light na bacia do rio Paraíba do Sul apresentam características de ocupação de grupos Gê no norte/nordeste do estado de São Paulo.

Em alguns deles a indústria cerâmica apresenta características de mais de uma tradição, como o sítio Água Branca com características de três tradições distintas, indicando que a classificação em tradições e fases - baseada em análises generalizantes da cerâmica, sem significados culturais - não fornece parâmetros suficientes para a compreensão dos processos internos e externos sofridos pelos grupos que habitaram esta região.

Uma vez que o conceito de tradição arqueológica dá ênfase na classificação dos objetos arqueológicos, optou-se pela expressão Sistema Regional de Povoamento, proposto por Morais (1999/2000), definido pela coordenação entre sítios ou conjunto de sítios de certa região, demonstrando relações concomitantes por contemporaneidade, similaridade ou complementaridade. $\mathrm{O}$ autor tomou como base operacional as denominadas Tradições Arqueológicas, mas com associação a outros aspectos dos sítios arqueológicos.

Ao definir os sistemas regionais de povoamento presentes na região Sudeste e elaborar uma síntese, Morais (1999/2000) sugeriu que as tradições Aratu, Sapucaí e Uru poderiam formar extenso sistema regional de povoamento de agricultores pré-coloniais, mesmo guardando-se suas peculiaridades específicas.

Em uma reflexão regional ampla, o sítio Água Branca pode ser inserido nesse Sistema Regional, chamado pelo autor de "Aratu-Sapucaí", mas desloca para o sul os limites sugeridos para essa ocupação. Os sítios Lagoa Preta I, Lagoa Preta II e Cachoeira de Emas 1 enquadram-se nesse mesmo sistema, embora seja necessário atentar que a similaridade na cultura material, nesse caso na indústria cerâmica, não está vinculada a uma homogeneidade étnica.

As questões levantadas pelo sítio Água Branca vão além: a diversidade do material arqueológico aponta para a ocorrência de influências externas, ligadas a contextos arqueológicos distintos, que ao se mesclarem formaram contextos locais específicos. Algumas questões interessantes podem ser alinhavadas como, por exemplo: qual a relação desse sítio com a ocupação Tupiguarani da região? A presença de alguns elementos, como ombros e caco-moído, indicaria que em algum momento houve concomitância nas ocupações? Em que medida a penetração branca na área afetou o cotidiano desse grupo? Esse impacto pode ser verificado nos vestígios arqueológicos?

A pesquisa etnohistórica mostrou que talvez não houvesse um contato direto entre a ocupação indígena da região - os denominados Caiapó - e a 
ocupação branca. A cerâmica do sítio Água Branca não apresenta influências européias, apesar de a datação ser do século XVIII. A pressão da colonização talvez tenha acelerado os movimentos dessas aldeias para o interior e os seus processos de diversificação cultural.

Essas conclusões concorrem com a idéia de São Paulo como uma "terra de fronteiras" para os grupos ceramistas que, a partir dos últimos séculos a.C., começam a ocupá-lo (Robrahn-González 2000). Esses grupos advindos de outras regiões trouxeram características próprias e, dentro deste contexto, os sítios de São Paulo apresentam particularidades relacionadas a um contexto de interação cultural.

Segundo Morais (2005), na metade norte do território paulista, os interflúvios das bacias dos rios Tietê e Grande marcam o eixo de uma larga faixa de sobreposição entre os sistemas Tupinambá e Guarani e um possível sistema Sapucaí, correlacionável à tradição arqueológica homônima; porém, a individualização deste 'sistema' ainda é altamente especulativa, em função do pequeno número de sítios pesquisados.

Afonso (2005), baseando-se nos mapas propostos por Morais (1999/2000), reelaborados em 2005 (Morais 2005), propôs uma região de influência de grupos Jê no norte de São Paulo abrangendo a bacia do rio Grande, incluindo a subbacia do rio Pardo, identificando uma área de contatos com ceramistas do Planalto Central.

A preocupação deve ser mais no sentido de caracterizar a indústria cerâmica e outras informações das ocupações ceramistas no norte de São Paulo do que pautar as pesquisas na tentativa, muitas vezes frustrada, de filiação a uma determinada "tradição" arqueológica. Os sítios ceramistas refletem contextos extra-regionais com influências do norte (Tupinambá), do sul e do oeste (Guarani) e do noroeste (Aratu-Sapucaí-Uru) de uma forma bastante complexa e que necessita ser melhor estudada.

\section{Agradecimentos}

Ao MAE/USP pelo apoio institucional, à Renovias Concessionária S.A. pelo auxílio financeiro (contrato com a USP) e à FAPESP pelas bolsas de Iniciação Científica e Mestrado para Camila Azevedo de Moraes. À equipe de campo (sítio Água Branca): Astolfo Gomes de Mello Araujo, Luciane Miwa Kamase, Robson Antonio Rodrigues, Nami Amenomori, Silvia Cristina Piedade, Dária Elânia Fernandes Barreto, José Paulo Jacob, João Avelar Lobato; Marinho Ribeiro Martins. À equipe de laboratório: José Luiz de Morais, Astolfo Gomes de Mello Araujo, Silvia Cristina Piedade, Dária Elânia Fernandes Barreto, José Paulo Jacob, João Avelar Lobato. A Sônia Tatumi e equipe da FATEC-SP pelas datações TL. A Henrique Kahn e Eliana Satiko Mano, do Laboratório de Caracterização Tecnológica (LCT)/ Departamento de Engenharia de Minas e de Petróleo da Escola Politécnica/Universidade de São Paulo, pelo trabalho com o Microscópio de Varredura Eletrônica (MEV). A Wagner Souza e Silva pelas fotografias de laboratório. A Maria do Carmo Mattos Monteiro dos Santos, pelas informações do levantamento arqueológico nos sítios de Casa Branca.

AFONSO, M.C.; MORAES, C.A. Água Branca Site: Cultural Interactions of ceramic groups at Northern São Paulo. Rev. do Museu de Arqueologia e Etnologia, São Paulo, 15-16: 59-71, 2005-2006.

ABSTRACT: The aim of this paper is to discuss ceramic occupations not associated to Tupiguarani Tradition in the north of São Paulo State, showing an influence from groups inhabiting Central Brazil. Special attention is devoted to the analyses of Água Branca archaeological site, located at Casa Branca (SP), as well as other sites, that were re-studied using approaches only recently recognized.

UNITERMS: Ceramics - Cultural interaction - São Paulo. 
AFONSO, M.C.; MORAES, C.A. O sítio Água Branca: interações culturais dos grupos ceramistas no norte do estado de São Paulo. Rev. do Museu de Arqueologia e Etnologia, São Paulo, 15-16: 59-71, 2005-2006.

\section{Referências bibliográficas}

AFONSO, M.C.

1988 A ocupação pré-histórica na região de Serra Azul e São Simão: um estudo geoarqueológico. Dissertação (Mestrado) - Faculdade de Filosofia, Letras e Ciências Humanas, Universidade de São Paulo, São Paulo.

1989 A ocupação de grupos caçadores-coletores no vale médio do rio Pardo (Estado de São Paulo). Revista de Pré-História, São Paulo, 6: 69-88.

2001 Resgate Arqueológico dos sítios Água Branca, Lambari I e Lambari II, Municípios de Casa Branca e Mococa - SP. Relatório encaminhado a Renovias Concessionária S.A. e IPHAN. MAE/USP.

2005 Um Olhar para a Arqueologia Pré-Histórica do Estado de São Paulo. Tese de Livre Docência. Museu de Arqueologia e Etnologia/ Universidade de São Paulo. São Paulo.

AFONSO, M.C.; MORAES, C.A.

2003 Uma Rodovia e Três Sítios Arqueológicos: um estudo da ocupação da Bacia do Rio Pardo (Nordeste de São Paulo). Anais da Sociedade de Arqueologia Brasileira. São Paulo, CD rom.

ALVES, M.A.; CALLEFFO, M.E.V.

1996 Sítio Arqueológico de Água Limpa, Monte Alto, São Paulo - Estruturas de combustão, restos alimentares e padrões de subsistência. Revista do Museu de Arqueologia e Etnologia, 6: 123-140.

ARNOLD, D.E.

1985 Ceramic theory and cultural process. Cambridge: Cambridge University Press.

\section{CALDARELLI, S.B}

1983 Aldeias tupiguarani no vale do rio Mogi Guaçu, Estado de São Paulo. Revista de PréHistória, São Paulo, 5: 37-124.

1999 Levantamento arqueológico em planejamento ambiental. Revista do Museu de Arqueologia e Etnologia, Suplemento 3: 347-369.

2001-2002 A Arqueologia do Interior Paulista evidenciada por suas Rodovias, Revista de Arqueologia, 14/15: 29-56.

2003a Os Sítios Arqueológicos e as Pesquisas. S.B. Caldarelli (Coord.) Arqueologia do Vale do Paraíba do Sul. SP-070 Rodovia Carvalho Pinto. DERSA Desenvolvimento Rodoviário S.A.: 8-46.

2003b A ocupação indígena do Vale do Paraíba, do período pré-colonial ao contato com o branco. S.B. Caldarelli (Coord.) Arqueologia do Vale do Paraíba do Sul. SP-070 Rodovia Carvalho Pinto. DERSA Desenvolvimento Rodoviário S.A. P. 210 - 213.

CALDARELLI, S.B.; NEVES, W.A.

1981 Programa de Pesquisas Arqueológicas no Vale do Rio Pardo. Revista de Pré-História, São Paulo, 3: 13-49.

CHMYZ, I.

1976 Terminologia arqueológica brasileira para a cerâmica. Cadernos de Arqueologia 1 (1), Universidade Federal do Paraná, Paranaguá. FERNANDES, S.C.G

2001 Estudo Tecnotipológico da cultura material das populações pré-históricas do vale do Rio Turvo, Monte Alto, São Paulo e a Tradição Aratu-Sapucaí. Dissertação de Mestrado. Faculdade de Filosofia, Letras e Ciências Humanas, Universidade de São Paulo.

GODOY, M.P.

1974 Contribuição à História Natural e Geral de Pirassununga. Pirassununga, Edição do Autor, Volume 1.

GOMES, D.M.C.

2003 A Cerâmica Indígena do Sítio Caçapava I. . S.B. Caldarelli (Coord.) Arqueologia do Vale do Paraíba do Sul. SP-070 Rodovia Carvalho Pinto. DERSA Desenvolvimento Rodoviário S.A.: 214-220.

MARANCA, S.; SILVA, A.M.; SCABELLO, A.

1994 Projeto Oeste Paulista de Arqueologia do Baixo e Médio Vale do Rio Tietê: Síntese dos Trabalhos Realizados. Revista do Museu de Arqueologia e Etnologia, 4: 223-226.

MORAES, C.A.

2004 Os sítios Água Branca e Lambari II no contexto da ocupação pré-histórica do médio vale do rio Pardo/ SP. Relatório Final de Iniciação Científica enviado à Fundação de Amparo à Pesquisa do Estado de São Paulo, Julho/2004.

2006 Estudo da variabilidade artefatual em sítios arqueológicos associados à Tradição Tupiguarani no nordeste do Estado de São Paulo. Relatório Final de Pesquisa de Mestrado entregue à Fundação de Amparo à Pesquisa do Estado de São Paulo, Agosto/2006.

MORAIS, J.L.

1995 Salvamento arqueológico na área de influência da PCH Moji-Guaçu. Revista do Museu de Arqueologia e Etnologia, São Paulo, 5: 77-98.

1999-2000 Arqueologia da região Sudeste. Revista da Universidade de São Paulo, São Paulo, 44: 194-217.

2005 Da Pré-História ao contato: sistemas regionais de povoamento indígena no território paulista. Resumos. XIII Congresso da Sociedade de Arqueologia Brasileira, Campo Grande.

RICE, P.M.

1987 Pottery analysis: a sourcebook. Chicago: Chicago University Press.

\section{ROBRAHN-GONZÁLEZ, E. M.}

1996 Os grupos ceramistas pré-coloniais do Brasil Central: Origens e Desenvolvimento. Tese de Doutorado, Faculdade de Filosofia, Letras e Ciências Humanas/USP. São Paulo. 
AFONSO, M.C.; MORAES, C.A. O sítio Água Branca: interações culturais dos grupos ceramistas no norte do estado de São Paulo. Rev. do Museu de Arqueologia e Etnologia, São Paulo, 15-16: 59-71, 2005-2006.

2000 São Paulo, Terra de Fronteiras: a ocupação de grupos ceramistas pré-coloniais. Anais do IX Congresso da Sociedade de Arqueologia Brasileira, Rio de Janeiro. CD-ROM.

ROBRHAN-GONZÁLEZ, E.M;AFONSO, M.C.; DE BLASIS, P.A.D.; FI-GUTI, L.; NEVES, E.G.; EGGERS, S.

1998 Água Vermelha: pesquisa arqueológica de salvamento. São Paulo: Museu de Arqueologia e Etnologia - Universidade de São Paulo, 87 p.

RYE, O.S.

1981 Pottery technology. Principles and reconstruction. Manuals on Archaeology 4, Washington DC, Smithsonian Inst. Press, Washington.

SCHIAVETTO, S.N.O.

2005 Levantamento Arqueológico no Médio MogiGuaçu e Médio Jacaré-Guaçu/SP: um primeiro olhar sobre os sítios cerâmicos. Anais do XIII Congresso de Arqueologia Brasileira, Campo Grande: Cd-Rom.

SCIENTIA.

2000 Relatório: Levantamento Arqueológico na Faixa de Domínio da Duplicação da Rodovia SP-340 - km 236,8 a 281,7. São Paulo, Scientia Consultoria Científica.

SINOPOLI, C. A.

1990 Approaches to archaeological ceramics, New York and London: Plenum Press.

Recebido para publicação em 18 de agosto de 2006.
SKIBO, J.M.

1992 Pottery Function: A Use-Alteration Perspective. New York: Plenum Press.

WÜST, I.

1990 Continuidade e mudança - para uma interpretação dos grupos ceramistas précoloniais da bacia do rio Vermelho, Mato Grosso. Tese de Doutorado, Faculdade de Filosofia, Letras e Ciências Humanas/USP, São Paulo/Goiânia.

ZANETTINIARQUEOLOGIA

2005 Programa de Diagnóstico Arqueológico do Sistema de Distribuição de Gás Natural, Eixo Matão - Luiz Antônio, São Paulo, Relatório Final.

ZANETTINI, P.E.; MORAES, C.A.

2005 Contribuição Para a Discussão em Torno da Cerâmica "Neobrasileira”: Algumas Reflexões Sobre a Louça Produzida na Capitânia de São Paulo Entre os Séculos XVII e XIX. Anais da XIII Reunião da Sociedade de Arqueologia Brasileira, Campo Grande: Cd-Rom.

2006 O Resgate dos Sítios Cachoeira de Emas 1 e 2 no âmbito da construção da Ponte sobre o rio Mogi Guaçu. Zanettini Arqueologia, Relatório Final de Pesquisa, Agosto de 2006, no prelo. 